\title{
Joannsin, a novel Kunitz-type FXa inhibitor from the venom of Prospirobolus joannsi
}

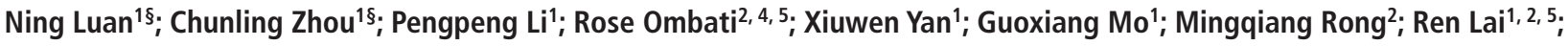 \\ Zilei Duan ${ }^{2,5}$; Ruiqiang Zheng ${ }^{3}$ \\ ${ }^{1}$ Key Laboratory of Microbiological Engineering of Agricultural Environment, Ministry of Agriculture, College of Life Sciences, Nanjing Agricultural University, Nanjing, Jiangsu, \\ China; ${ }^{2}$ Key Laboratory of Animal Models and Human Disease Mechanisms of Chinese Academy of Sciences \& Yunnan Province, Kunming Institute of Zoology, Kunming, Yunnan, \\ China; ${ }^{3}$ Intensive Care Unit, Subei People's Hospital of Jiangsu Province, Yangzhou, Jiangsu, China; ${ }^{4}$ Sino-African Joint Research Center, CAS, Kunming Institute of Zoology, \\ Kunming, Yunnan, China; ${ }^{5}$ University of Chinese Academy of Sciences, Beijing, China
}

\begin{abstract}
Summary
The repugnatorial glands of millipedes release various defensive chemical secretions. Although varieties of such defensive secretions have been studied, none of them is protein or peptide. Herein, a novel factor Xa (FXa) inhibitor named joannsin was identified and characterised from repugnatorial glands of Prospirobolus joannsi. Joannsin is composed of 72 amino acid residues including six cysteines, which form three intra-molecular disulfide bridges. It is a member of Kunitztype protease inhibitor family, members of which are also found in the secretory glands of other arthropods. Recombinant joannsin exhibited remarkable inhibitory activity against trypsin and FXa with a Ki of
\end{abstract}

\section{Correspondence to:}

Ren Lai, Zilei Duan, or Ruiqiang Zheng

Key Laboratory of Microbiological Engineering of Agricultural Environment

Ministry of Agriculture, College of Life Sciences, Nanjing Agricultural University

Nanjing 210095, Jiangsu, China

Tel./Fax: +86 25843968

E-mail: rlai72@njau.edu.cn (R. L.), duanzileikiz@126.com (Z.D.) or

13952721411@163.com (R.Z.)

$\S \quad$ These authors contributed equally to this paper.
$182.7 \pm 14.6$ and $29.5 \pm 4.7 \mathrm{nM}$, respectively. Joannsin showed strong anti-thrombosis functions in vitro and in vivo. Joannsin is the first peptide component in millipede repugnatorial glands to be identified and is a potential candidate and/or template for the development of antithrombotic agents. These results also indicated that there is Kunitztype protease inhibitor toxin in millipede repugnatorial glands as in other arthropods secretory glands.

\section{Keywords}

Millipede, repugnatorial gland, Kunitz-type inhibitor, factor Xa, thrombosis

Received: November 9, 2016

Accepted after major revision: February 19, 2017

Epub ahead of print: March 9, 2017

https://doi.org/10.1160/TH16-11-0829

Thromb Haemost 2017; 117: 1031-1039

\section{Introduction}

Arthropods, common on land and in water, are rich in biologically active peptides including protease inhibitors $(1,2)$. Millipedes are widely distributed in the world. Most of them possess defensive/repugnatorial glands in the form of integumental sacs arranged segmentally along the length of the body. These glands provide the best protection from their predators (3). There are various chemical toxins such as 1, 4-benzoquinones, phenols, hydrogen cyanide, quinazolinones, alkaloids, benzaldehyde, benzoyl cyanide, benzoic acid, mandelonitrile, and mandelonitrile benzoate in the defensive glands $(3,4)$. Most of these compounds might be produced by symbiotic microbes and readily available through food intake or aspiration (5). So far, no peptide or protein has been investigated in the defensive glands (6). Many bioactive peptides and/or proteins with functions related to defense, preying and blood-sucking have been identified from the arthropods' secretory glands, including salivary glands and venom glands. It is hypothesised that the repugnatorial gland, which is a specialized secretory gland in millipedes, contains bioactive peptides and/or proteins. The current work prospects gene-encoded proteins or peptides from the repugnatorial glands of the Prospirobolus joannsi, which is widely distributed in China with great abundance.

\section{Materials and methods}

\section{Anatomical studies}

P. joannsi (individual weight of 5-6 g) were collected from the forest of Jiangsu Province of China. The millipedes were dissected in phosphate-buffered saline (PBS) $(150 \mathrm{mM} \mathrm{NaCl}, 2.7 \mathrm{mM} \mathrm{KCl}$, $1.5 \mathrm{mM} \mathrm{KH}_{2} \mathrm{PO}_{4}$, and $\left.8 \mathrm{mM} \mathrm{K}_{2} \mathrm{HPO}_{4}, \mathrm{pH} 7.2\right)$ immediately. The sacs of defensive glands were displayed after dissecting the millipedes and removing the innards carefully according to the described method (3).

\section{Collection of secretions from the millipede repugnatorial glands}

The secretions (crude sample) were collected manually by stimulating the repugnatorial glands of the millipedes using a $3 \mathrm{~V}$ alternating current according to our previous report (7). The crude 
sample was filtrated by the Centrifugal Filter Devices (Millipore, $3000 \mathrm{NMWL}$ ), and the components with a molecular weight greater than $3000 \mathrm{Da}$ (crude extracts) were kept for further analysis.

\section{cDNA library construction and sequencing}

The defensive glands of $P$. joannsi were dissected as described above and cDNA was prepared as detailed in our previous study (8). Total RNA was extracted from the defensive glands of five millipedes using TRIzol (Life Technologies Ltd., Carlsbad, CA, USA) and used to prepare cDNA using a SMART ${ }^{\mathrm{me}}$ PCR cDNA synthesis kit (Clontech, Palo Alto, CA, USA). cDNA library was constructed by using a Creator SMART ${ }^{\mathrm{TM}}$ CDNA Library Construction Kit (Clontech) according to manufacturer's instructions. A cDNA library of about $3 \times 10^{6}$ independent colonies was produced. The clones with cDNA $>350 \mathrm{bp}$ were selected and sequenced on an ABI PRISM 377 DNA sequencer (Applied Biosystems, Foster City, CA, USA).

\section{Expression and purification of recombinant joannsin}

The DNA sequence encoding recombinant joannsin was synthesised (Sangon Biotech, Co., Ltd. Shanghai, China). As described in our previous study (9), a chemical cleavage site (-DP-) for form-

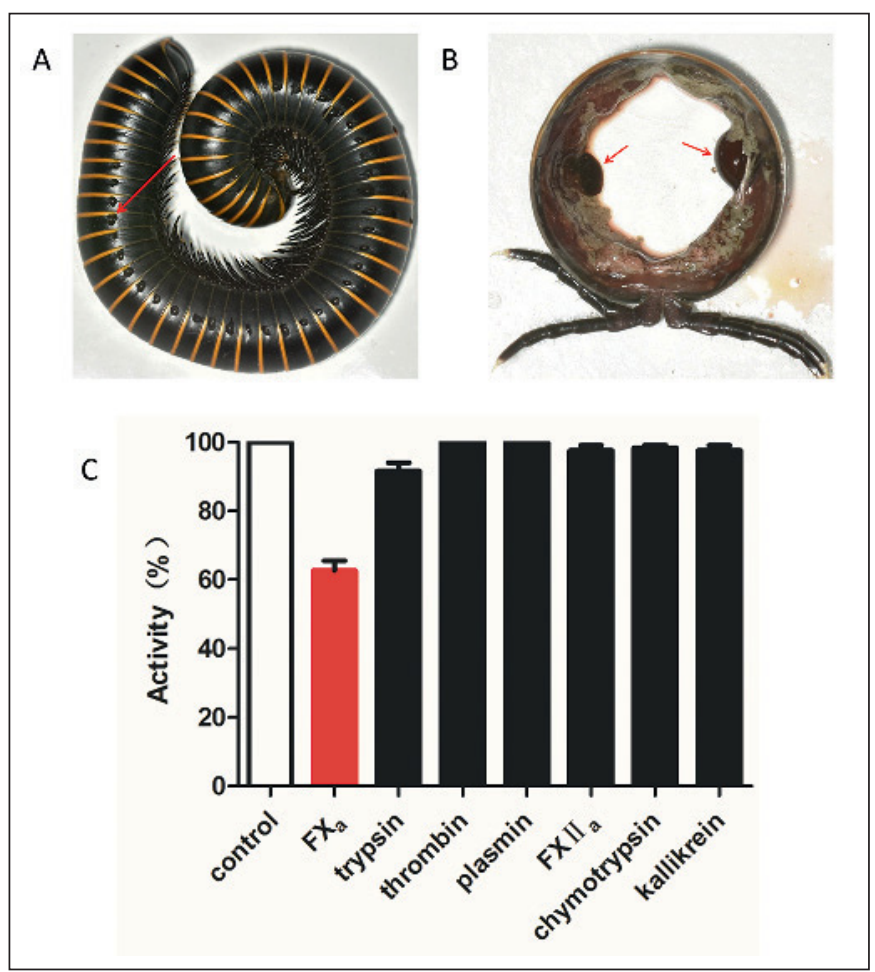

Figure 1: Repugnatorial glands in P. joannsi and FXa-inhibiting activity in its secretions. A) Defensive secretions from the millipede repugnatorial glands. B) Pairs of defensive glands in each body somite of the millipede are indicated by the red arrow. C) The components containing FXa-inhibiting activity. At the concentration of $\sim 0.1 \mathrm{mg} / \mathrm{ml}$, the mixture components significantly inhibited FXa. ic acid was designed at right upstream to joannsin coding sequence. The joannsin/pET-32a $(+)$ construct was transformed into Escherichia coli strain BL-21 (DE3) for recombinant expression. $50 \%$ formic acid (v/v) treatment was used to release recombinant joannsin from the fusion protein. The hydrolysed joannsin was purified by a Sephadex G-50 (Superfine, Amersham Biosciences, Piscataway, NJ, USA; $2.6 \mathrm{~cm} \times 100 \mathrm{~cm}$ ) gel filtration column eluted by $0.1 \mathrm{M}$ phosphate buffer, $\mathrm{pH} 6.0$ (PBS) and $\mathrm{C}_{4}$ reverse phase high performance liquid chromatography (RP-HPLC, Unisil $\mathrm{C}_{4}$ column, $5 \mu \mathrm{m}$ particle size, $10 \mathrm{~mm} \times 250 \mathrm{~mm}$ ) eluted with a gradient of increasing acetonitrile concentration containing $0.1 \%(\mathrm{v} / \mathrm{v})$ trifluoroacetic acid (TFA). Lyophilised HPLC fractions were dissolved in $0.1 \%$ trifluoroacetic acid/water. $0.5 \mu \mathrm{L}$ sample was spotted onto a matrix-assisted laser desorption ionisation time-offlight (MALDI-TOF) plate with $0.5 \mu \mathrm{l}$ a-cyano-4-hydroxycinnamic acid matrix ( $10 \mathrm{mg} / \mathrm{ml}$ in $60 \%$ acetonitrile). Spots were analysed by an UltraFlex I mass spectrometer (Bruker Daltonics, Billerica, MA, USA) in a positive ion mode, with $\pm 0.06 \%$ accuracy of mass determinations.

\section{Blood coagulation time assay}

Blood recalcification time was measured according to the method described by Gulliani et al. (10). Briefly, $20 \mu \mathrm{l}$ of platelet-poor plasma (PPP) collected from healthy human subjects was dispensed into round-bottomed 96-well plates, and then the testing sample which was dissolved in $80 \mu \mathrm{l}$ of HEPES buffer (with $0.15 \mathrm{M} \mathrm{NaCl}$, pH 7.4) was added to the plates. After incubation for 10 minutes (min) at room temperature, $50 \mu \mathrm{l}$ of $0.025 \mathrm{M}$ calcium chloride $\left(\mathrm{CaCl}_{2}\right)$ was added to the plates and the clotting time was recorded. The activated partial thromboplastin time (APTT) assay was performed according to the previous method (12). APTT reagent (50 $\mu$ l) was incubated with the mixture of PPP $(40 \mu \mathrm{l})$ and testing sample (10 $\mu \mathrm{l})$ at $37^{\circ} \mathrm{C}$ for $3 \mathrm{~min}$, and clotting time was recorded after the addition of $50 \mu \mathrm{l}$ of $0.025 \mathrm{M} \mathrm{CaCl}_{2}$. For prothrombin time (PT) assay, PT reagent $(50 \mu \mathrm{l})$ was added to the incubated mixture at $37^{\circ} \mathrm{C}$ for 3 min of PPP (40 $\mu \mathrm{l})$ and testing sample $(10 \mu \mathrm{l})$, and clotting time was recorded. All the analyses above were monitored by the Microplate Spectrophotometer (BioTek Instrument, Inc., Winoos$\mathrm{ki}, \mathrm{VT}, \mathrm{USA}$ ) at the absorbance of $650 \mathrm{~nm}$.

\section{Serine protease inhibitory testing}

According to our previous report (9), experiments were assayed in buffer $(0.05 \mathrm{M}$ Tris- $\mathrm{HCl}, \mathrm{pH} 7.8)$ at $37^{\circ} \mathrm{C}$. The proteases (Factor Xa, $0.1 \mathrm{nM}$, Enzyme Research Laboratories, South Bend, IN, USA, HFXa 1011; trypsin, 10 nM, Sigma, St. Louis, MO, USA, T4665; thrombin, 10 nM, Sigma, T4393; plasmin, 10 nM, Sigma, P1867; Factor XIIa, $10 \mathrm{nM}$, Enzyme Research Laboratories, HFXIIa 1212a; chymotrypsin, $400 \mathrm{nM}$, Sigma, CHY5S; kallikrein, $400 \mathrm{nM}$, Enzyme Research Laboratories, HPKa 1303) and different amounts of joannsin (final concentrations ranging from 0.0 to $0.262 \mu \mathrm{M}$ ) were pre-incubated for $10 \mathrm{~min}$ at $37^{\circ} \mathrm{C}$. After incubation of the inhibitor with the enzyme for $30 \mathrm{~min}$, the reaction was initiated by the addition of $0.5 \mathrm{mM}$ substrate F3301 
$\left(\mathrm{CH}_{3} \mathrm{OCO}-\mathrm{D}\right.$-CHA-Gly-Arg-pNA-AcOH, Sigma) for FXa, B3133 ( $N$-benzyl-L-arginine-4-nitroanilide-hydrochride-pNA, Sigma) for trypsin, $H$ - $D$-Phe-Pip-Arg- $p \mathrm{Na} \cdot 2 \mathrm{HCl}$ (Hyphen Biomed, Neuville-sur-Oise, France) for thrombin, G8148 (Gly-Arg-p-nitroanilide dihydrochloride, Sigma ) for plasmin, $H$-D-Pro-Phe-ArgpNA.2HCl (Hyphen Biomed, France) for FXIIa, S1899 (N-Succinyl-Gly-Gly-Phe-p-nitroanilide, Sigma) for chymotrypsin, and C9521 (Z-Phe-Arg-7-amido-4-methylcoumarin hydrochloride, Sigma) for kallikrein. The initial rate of product formation in each reaction was monitored continuously at $405 \mathrm{~nm}$ for $2 \mathrm{~min}$. The inhibition constant $K i$ was determined according to the Dixon method (11). To further study the inhibition of joannsin on FXa, the physiological substrate human prothrombin (Enzyme Research Laboratory, HP 1002) was used. The reaction was assayed in buffer $(0.05 \mathrm{M}$ Tris- $\mathrm{HCl}, \mathrm{pH} 7.8)$ at $37^{\circ} \mathrm{C}$. After incubation of $\mathrm{FXa}(10 \mathrm{nM})$ and joannsin $(0,10,20,50 \mathrm{nM})$ for $30 \mathrm{~min}$, human prothrombin $(10 \mathrm{nM})$ was added to the mixture and incubated for $5 \mathrm{~min}$, and then the reaction was stopped with the addition of $5 \times$ SDS-loading buffer. After boiling for $5 \mathrm{~min}$, the mixtures were checked by the SDS-PAGE.

\section{Anti-thrombosis in mouse model}

Carrageenan-induced mouse tail thrombosis model (13) was used in this experiment. Apixaban and $0.9 \%$ saline were used as positive control and blank control, respectively. Testing sample with different concentrations was injected intravenously into male Kunming mice $(\mathrm{n}=8,20-25 \mathrm{~g})$. After $30 \mathrm{~min}$, mice were intraperitoneally injected with $100 \mu \mathrm{l}(1 \%)$ k-Carrageenan (type I, Sigma) dissolved in $0.9 \% \mathrm{NaCl}$ with a dose of $60 \mathrm{mg} / \mathrm{kg}$ to induce throm- bosis in the tail. Six hours (h) after the injection of $\mathrm{k}$-Carrageenan, the testing sample was injected into mice by caudal vein again. The length of thrombus in mouse tail was measured at $12 \mathrm{~h}$ and $24 \mathrm{~h}$ after treatment, respectively. All the experimental protocols using animals in this work were approved by the Animal Care and Use Committee at Kunming Institute of Zoology, Chinese Academy of Sciences (SMKX-2015022).

\section{Statistical analysis}

Data were assessed for statistical significance using Student's (unpaired) $t$-test. Results were reported as mean $\pm S E$ with significance accepted at $\mathrm{p}<0.05$.

\section{Results}

\section{Anatomical studies}

Copious secretion was observed in the millipede repugnatorial glands after stimulating by a $3 \mathrm{~V}$ alternating current ( $>$ Figure 1A). There was a pair of defensive glands in each body somite of the millipede ( $\triangleright$ Figure $1 \mathrm{~B})$.

\section{FXa inhibiting activity in the secretions of the millipede defensive glands}

Under the assay conditions, at the concentration of $\sim 0.1 \mathrm{mg} / \mathrm{ml}$, the crude extracts of the defensive secretions showed significant inhibitory activity on FXa ( $\$ Figure 1C), indicating that there are components that inhibit FXa in the crude extracts. However, there
Figure 2: Primary structure of joannsin (A) and sequence alignment with other Kunitztype serine protease inhibitors (B). Mature joannsin is boxed, and the stop codon is indicated by a bar (-). The identical amino acid residues are indicated by the symbol (\#). Cysteine residues are highlighted in grey and the trypsin interaction sites are shown in red.
A 1 atggacaataggtttgtggcactgcttaccgtcttagtcatcatgcacacactgacattc

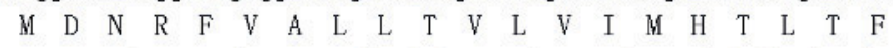

61 agcagagg tcaagcatggcagaattacta.taggcctagcogtgceggt tat tcatactgc \begin{tabular}{llllllllllllllllllll|}
$S$ & $R$ & $G$ & $Q$ & $A$ & $W$ & $Q$ & $N$ & $Y$ & $Y$ & $R$ & $P$ & $S$ & $R$ & $A$ & $G$ & $Y$ & $S$ & $Y$ & $C$ \\
\cline { 2 - 7 }
\end{tabular}

121 tacgatgactacgacattgggccctgcagagcccgttttcgtcagtggtat tataataga \begin{tabular}{|llllllllllllllllllll|}
\hline $\mathrm{Y}$ & $\mathrm{D}$ & $\mathrm{D}$ & $\mathrm{Y}$ & $\mathrm{D}$ & $\mathrm{I}$ & $\mathrm{G}$ & $\mathrm{P}$ & $\mathrm{C}$ & $\mathrm{R}$ & $\mathrm{A}$ & $\mathrm{R}$ & $\mathrm{F}$ & $\mathrm{R}$ & $\mathrm{Q}$ & $\mathrm{W}$ & $\mathrm{Y}$ & $\mathrm{Y}$ & $\mathrm{N}$ & $\mathrm{R}$ \\
\hline
\end{tabular}

181 cgtaccggtgaatgtgaaatctttttctacgggggatgtttgggaacgacaataaat \begin{tabular}{|llllllllllllllllllll|}
\hline$R$ & $T$ & $G$ & $E$ & $C$ & $E$ & $I$ & $F$ & $F$ & $Y$ & $G$ & $G$ & $C$ & $L$ & $G$ & $N$ & $D$ & $N$ & $K$ & $Y$ \\
\hline
\end{tabular}

241 gagtcaaaagaagaatgcgaatatatctgtaagaaattgctcacgtagcaagagtgttca \begin{tabular}{|llllllllllllllll|}
\hline E & S & K & E & E & C & E & Y & I & C & K & K & L & L & T & - \\
\hline
\end{tabular}

301 ctaattatgactgttgacgaacacgtgttaatttgttcaagcag taa.acggatcatgaca gcacaatgaaatataaaattgttggaactgttactcatg

B

Joannsin carrapatin Boophilin-G2 heamalin Trypsin interaction site QATQNYYRPSRAGYSYCYDDYDIGPCRARFRQWYYNRRTGBCEIFFYGGCLGNDNKYESKEBCEYIC- -



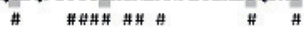


were only $\sim 1-3 \%$ total proteins in the crude extracts and the sample was insufficient for purification of native FXa inhibitors from the secretions. Other approaches including cDNA cloning and recombinant expression were used to identify and characterise potential FXa inhibitors.

\section{Primary structure of joannsin}

A cDNA encoding a protein precursor composed of 95 amino acid (aa) residues was found ( Figure $2 \mathrm{~A}$ ). After online analysis to predict cleavage sites and a signal peptide/non-signal peptide by
A

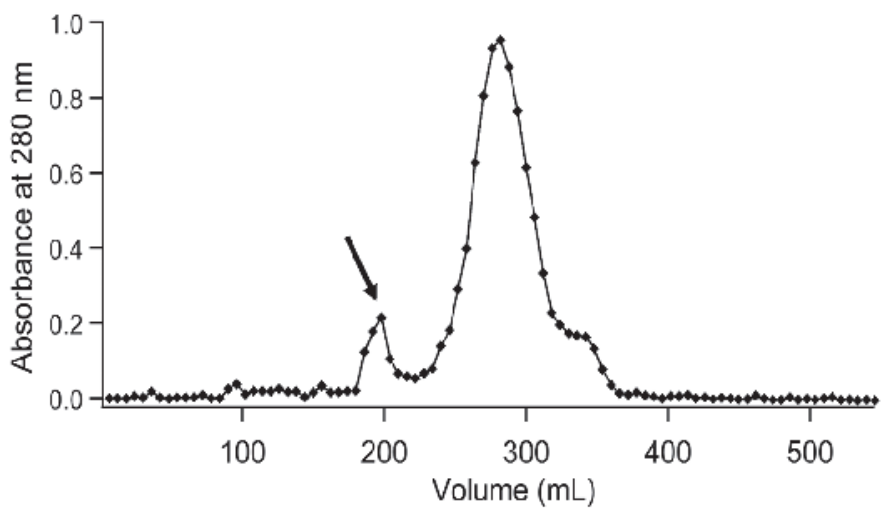

B

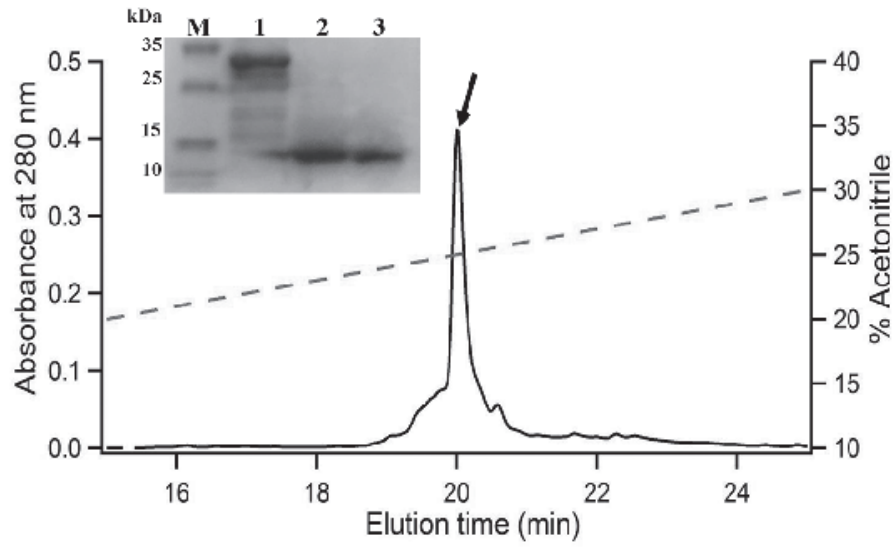

C

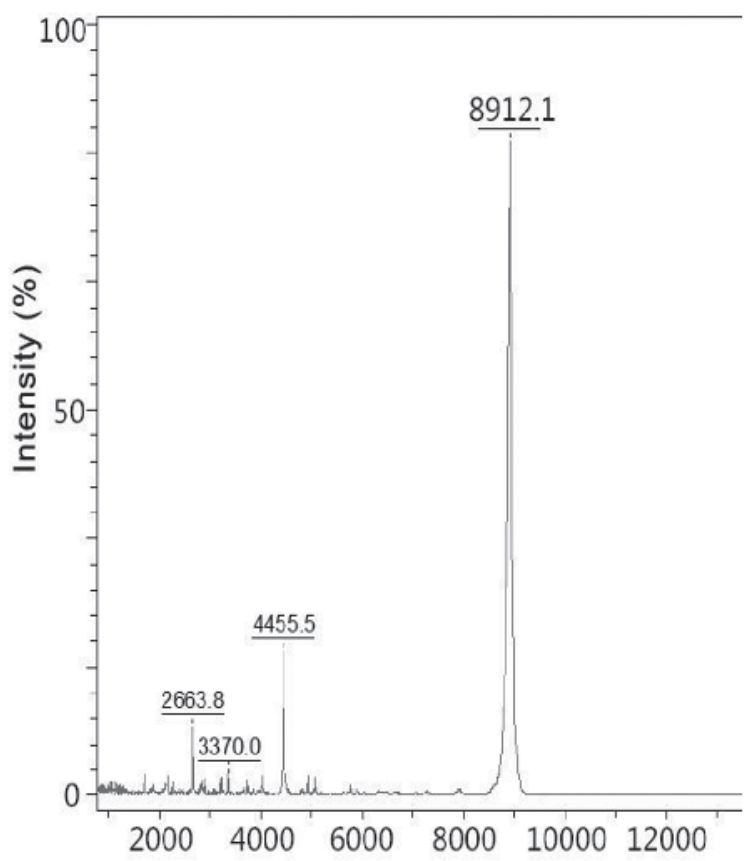

Figure 3: Recombinant expression of joannsin. Recombinant joannsin was purified by Sephadex G-50 gel filtration (A) and C4 RP-HPLC (B), indicated by an arrow. SDS-PAGE of samples after each purification (inserted in B): collected fusion protein purified with affinity (line 1); after chemical cleavage, recombinant joannsin was purified by a Sephadex G-50 (line 2); recombinant joannsin purified by a C4 RP-HPLC (line 3). The purified recombinant joannsin was subjected to MALDI-TOF mass spectrometry analysis (C). 
the SignalP 4.1 Server tool (http://www.cbs.dtu.dk/services/Sig nalP/), a hypothetical 23-aa signal peptide and a hypothetical 72-aa mature peptide named joannsin were obtained. BLAST search indicated that joannsin shared high homology with other known Kunitz-type protease inhibitors, which are thrombin inhibitors from salivary glands of blood-sucking ticks (14-17) ( $>$ Figure 2B). Especially, there is a putative trypsin interaction site present in other serine protease inhibitors. The distribution motif of six cysteines in joannsin is also identical to other serine protease inhibitors. Based on the sequence alignment, joannsin may contain inhibitory ability on serine proteases, especially on blood coagulation factors.

\section{Expression and purification of recombinant joannsin}

The joannsin/pET-32a (+) construct was transformed into the $E$. coli strain BL-21 (DE3) for recombinant expression. The recombinant joannsin was expressed by the induction of IPTG $(1 \mathrm{mM})$ and purified from the soluble fraction of the E. coli lysate. The recombinant protein was isolated on a His-binding resin $\mathrm{Ni}^{2+}$ affinity column and hydrolysed by $50 \%$ formic acid. The products were first separated by the Sephadex G-50 gel filtration column ( $>$ Figure $3 \mathrm{~A}$ ), and then purified further by the $\mathrm{C}_{4}$ RP-HPLC ( $>$ Figure
3B). After each purification, SDS-PAGE was used to identify the quality of collected samples (inserted in the Figure $3 \mathrm{~B}$ ). The purified joannsin was subjected to matrix-assisted laser desorption ionisation time-of-flight (MALDI-TOF) mass spectrometry (MS) analysis, which gave an observed molecular mass of 8911.1 ( Figure 3C) by using a positive ion and linear mode. The theoretically predicted molecular mass of joannsin is $8916.9 \mathrm{Da}$. Considering that the sequence contains six cysteine residues, which likely form three intra-molecular disulfide bridges as found in other Kunitztype serine protease inhibitors, the theoretically predicted molecular mass of joannsin containing three intra-molecular disulfide bridges should be $8910.9 \mathrm{Da}$, which corresponded with the observed molecular mass.

\section{Joannsin prolonged blood coagulation time}

The influence of joannsin to blood coagulation was explored through the recalcification time, APTT and PT assay. Compared with normal recalcification time of $\sim 10 \mathrm{~min}$, recalcification time was significantly prolonged by $0.125 \mathrm{mg} / \mathrm{ml}$ joannsin, and no coagulation was observed even at $15 \mathrm{~min}$ ( $>$ Figure 4A). Normal APTT is $~ 30$ seconds (s). However, no coagulation appeared even at $120 \mathrm{~s}$ after $0.125 \mathrm{mg} / \mathrm{ml}$ joannsin treatment ( Figure $4 \mathrm{~B}$ ).

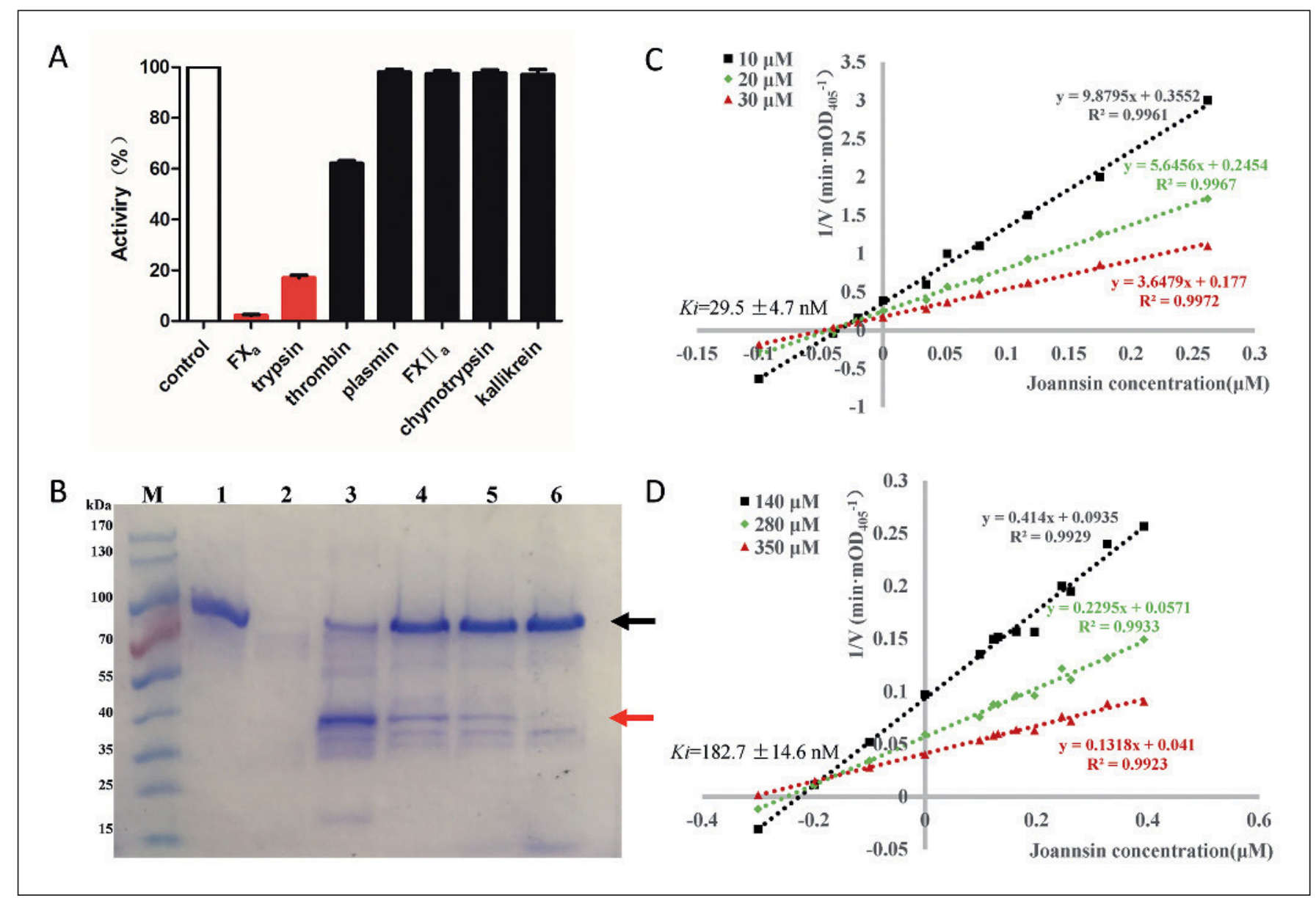

Figure 4: Coagulation effect of joannsin. Compared with the control group, the recalcification time (A), APTT (B) and PT (C) were prolonged. 
Compared with the normal PT of $\sim 10 \mathrm{~s}$, the PT induced by 0.125 $\mathrm{mg} / \mathrm{ml}$ joannsin was $\sim 60 \mathrm{~s}$ ( $>$ Figure $4 \mathrm{C}$ ).

\section{Protease inhibitory activity of joannsin}

The inhibition activity of joannsin to a diversity of proteases was further explored. We confirmed that joannsin strongly inhibited the activity of FXa and trypsin and moderately inhibited the activity of thrombin ( Figure 5A). It had no effect on plasmin, FXIIa, chymotrypsin, and kallikrein, which are related with blood coagulation, inflammation, or digestion. With the incubation of joannsin and FXa, it was suggested that joannsin inhibited the activity of FXa to its physiological substrate human prothrombin in a dosedependent manner ( Figure 5B). Enzymatic kinetic studies showed that joannsin was a non-competitive inhibitor towards FXa and trypsin with $K i$ of $29.5 \pm 4.7$ and $182.7 \pm 14.6 \mathrm{nM}$, respectively ( Figure 5C, D).

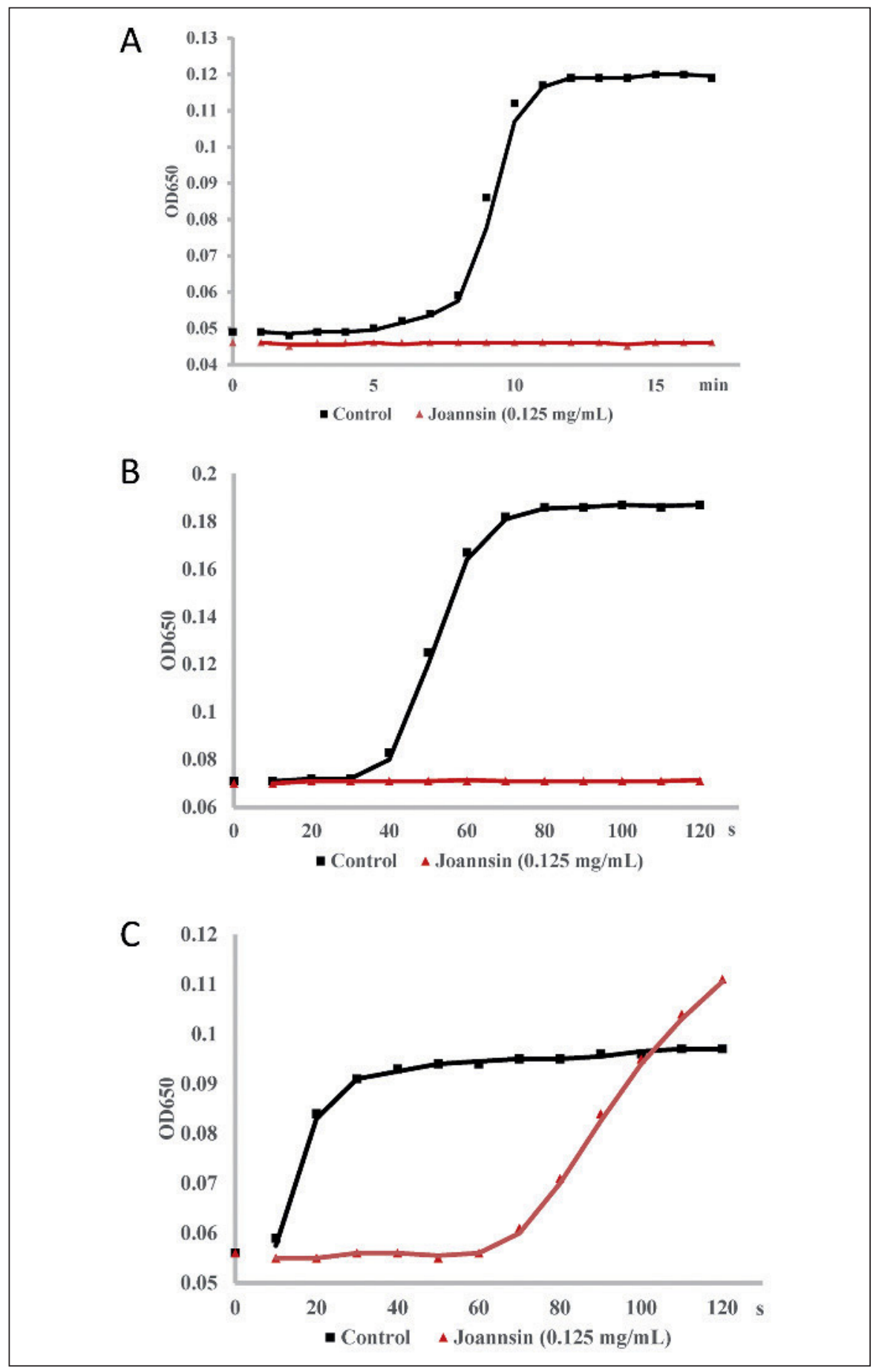

Figure 5: Protease inhibiting activity of joannsin. The effect of joannsin on FXa, trypsin, thrombin, plasmin, FXIla, chymotrypsin and kallikrein with the chromogenic substrate (A). SDSPAGE after the reaction of joannsin and FXa (B): human prothrombin (line 1); FXa (line 2); joannsin inhibited the activity of FXa to human prothrombin with different concentrations $(0 \mathrm{nM}$ : line 3; $10 \mathrm{nM}$ : line 4; $20 \mathrm{nM}$ : line5; $50 \mathrm{nM}$ : line 6), black arrow and red arrow indicated human prothrombin and thrombin, respectively. According to the Dixon method, the Ki of joannsin towards FXa and trypsin is $29.5 \pm 4.7 \mathrm{nM}$ (C) and $182.7 \pm$ $14.6 \mathrm{nM}(\mathrm{D})$, respectively. 


\section{Joannsin inhibited thrombus formation}

As shown in Figure 6, recombinant joannsin inhibited thrombosis in a dose-dependent manner in carrageenan-induced mouse tail thrombosis model. After $12 \mathrm{~h}$ injection of joannsin, thrombus formation was inhibited by $28.3 \%, 50.0 \%$ and $70.0 \%$ at the dosage of $2(67.33 \mu \mathrm{M}), 4(134.66 \mu \mathrm{M})$ and $6 \mathrm{mg} / \mathrm{kg}(201.99 \mu \mathrm{M})$, respectively, compared with the $38.3 \%$ inhibitory rate induced by $0.2 \mathrm{mg} /$ $\mathrm{kg}(130.58 \mu \mathrm{M})$ apixaban, which is a clinical FXa inhibitor ( Figure $6 \mathrm{~A}$ ). At the time of $24 \mathrm{~h}, 26.1 \%, 54.2 \%$ and $61.1 \%$ thrombus formation was inhibited by 2, 4 and $6 \mathrm{mg} / \mathrm{kg}$ joannsin, respectively. The thrombus formation inhibition by $0.2 \mathrm{mg} / \mathrm{kg}$ apixaban is $44.4 \%$ ( Figure 6B). The representative actual thrombus length of each group at $24 \mathrm{~h}$ was measured and the photos taken $(-$ Figure $6 \mathrm{C}$ ).

\section{Discussion}

Many arthropods contain specialised secretory glands, which have been found in groups of chelicerata, hexapoda, myriapoda and insects (18). For instance, horseflies $(19,20)$ and ticks $(21,22)$ have salivary glands containing bioactive peptides or/and proteins with functions (i.e. anti-thrombosis, analgesia, and anti-inflammation) to facilitate blood-sucking; wasps $(23,24)$, centipedes $(25-27)$, scorpions $(8,28)$, and spiders (29-32) have venomous glands containing peptides or/and proteins to exert defensive and predatory functions. Many components in those glands are small peptides in which disulfide bonds form the scaffolds which are referred to as disulfide-rich domains (21). Particularly, many of these small peptides belong to the group of Kunitz-type serine protease inhibitors which possess diverse functions, they act on voltage-gated ion channels, proteases, coagulation factors, receptors, and so on (33-35). Significantly specialised repugnatorial glands in the body of millipedes are considered as defensive organs. Many chemical compounds exerting defensive functions have been identified from repugnatorial glands of millipedes $(3,4)$. Most of the compounds are originated from foods. Limited information is available on peptides or proteins from repugnatorial glands of millipedes.

A Kunitz-type serine protease inhibitor (joannsin) was identified and characterized from the defensive glands of the P. joannsi. Joannsin is a peptide containing 72 amino acid residues including three intra-molecular disulfide bridges, which form disulfide-rich domains as found in other secretory glands of venomous or bloodsucking arthropods (21). Joannsin shares significant sequence similarity with thrombin inhibitors from salivary glands of ticks, a group of blood-sucking arthropods (14-17). Among the seven tested serine proteases, joannsin showed inhibitory activity on two coagulation factors (thrombin and FXa) and trypsin ( Figure 5). It showed the strongest ability to inhibit FXa especially. Amblyomin-X, TFPI (tissue factor pathway inhibitor) and joannsin all belong to the Kunitz-type serine protease inhibitor, but they have different $K i$ to FXa: $3.9 \mu \mathrm{M}$ for Amblyomin-X; $1.24 \mathrm{nM}$ for TFPI; 29.5 $\pm 4.7 \mathrm{nM}$ for joannsin (36-37). The structural and functional simi-

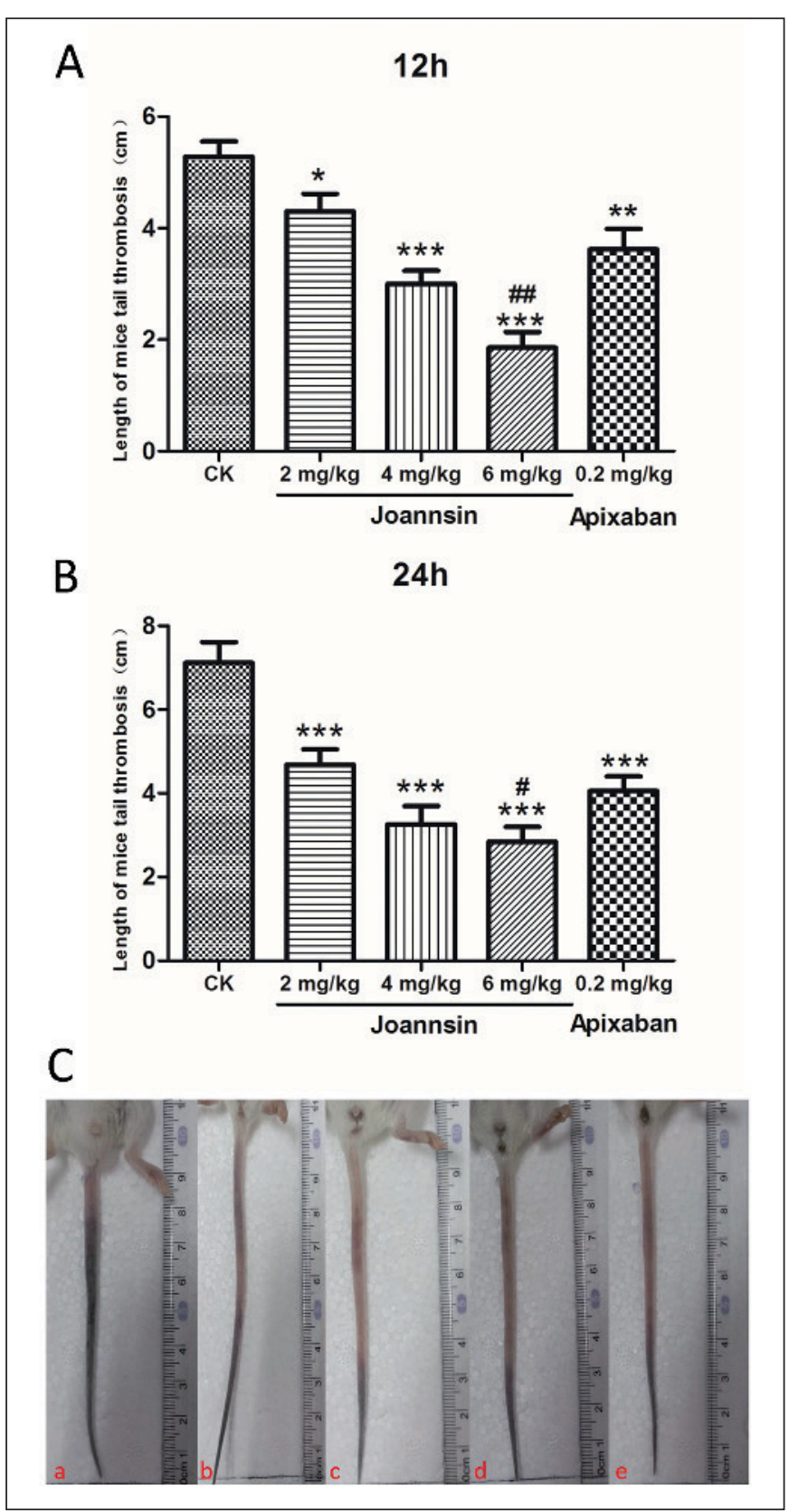

Figure 6: Joannsin inhibited thrombus formation in vivo. Joannsin inhibited carrageenan-induced thrombosis in mouse tail at 12 (A) and 24 (B) $\mathrm{h}$ after injection in a dose-dependent manner. (C) The representative thrombus in the mouse tail at $24 \mathrm{~h}$. (a) The control group, (b, c, d) the joannsin groups with different concentrations ( $2 \mathrm{mg} / \mathrm{kg}, 4 \mathrm{mg} / \mathrm{kg}$ and $6 \mathrm{mg} / \mathrm{kg}$, respectively), (e) the group of apixaban $(0.2 \mathrm{mg} / \mathrm{kg})$. Data were presented as mean $\pm \mathrm{SE}$. * $\mathrm{P}<0.05,{ }^{* *} \mathrm{P}<0.01,{ }^{* * *} \mathrm{P}<0.001$ compared with $\mathrm{CK}$, \# $\mathrm{P}<0.05$, \#\# $\mathrm{P}<$ 0.01 , compared with Apixaban. Analysed by student's t test for two-sample comparison.

larity of Kunitz-type serine protease inhibitors in both ticks and millipedes may imply their evolution connection, which opens up a new avenue for further study. FXa plays a key role in blood coagulation and is an important target for the development of antithrombosis agents. As illustrated in Figure 6, in vivo anti- 


\section{What is known about this topic?}

- The repugnatorial glands of millipedes release various defensive chemical secretions, such as 1, 4-benzoquinones, phenols, hydrogen cyanide, quinazolinones, alkaloids, benzaldehyde, benzoyl cyanide, benzoic acid, mandelonitrile, and mandelonitrile benzoate, to provide the best protection from their predators.

- Although varieties of such defensive secretions have been studied, none of them is protein or peptide.

- We hypothesised that the repugnatorial gland, which is a specialised secretory gland in millipedes, contains bioactive peptides and/or proteins.

\section{What does this paper add?}

- In this study, we have prospect a novel coagulant factor Xa (FXa) inhibitor named joannsin, which from the protein components of the defensive chemical secretions of Prospirobolus joannsi.

- To our knowledge, so far, this is the first peptide investigated in the repugnatorial glands of the millipede. As a Kunitz-type protease inhibitor, joannsin exhibited remarkable inhibitory activity against trypsin and FXa with a $\underline{\mathrm{Ki}}$ of $182.7 \pm 14.6$ and $29.5 \pm 4.7$ $\mathrm{nM}$, respectively.

- Besides, joannsin showed strong anti-thrombosis functions in vitro and in vivo.

- Our findings support that joannsin can be a potential candidate and/or template for the development of anti-thrombotic agents.

thrombosis ability of joannsin is comparable with that of apixaban, a clinical anti-thrombotic agent. Three intra-molecular disulfide bridges in the small peptide of joannsin may render high stability in vivo, which combined with the potential anti-FXa and anti-trypsin abilities may make joannsin an excellent candidate and/or template to develop anti-thrombosis drugs.

\section{Acknowledgements}

We gratefully acknowledge the assistance of Mingqian Fang, Mengrou Chen, Haoran Bao and Lin Jin from Life Sciences College of Nanjing Agricultural University for collecting Prospirobolus joannsi.Financial support: This work was supported by Sino-African Joint Research Center, Grant SAJC201606, National Natural Science Foundation Grant 31201717, Jiangsu Province Grant Q0201600440, and Chinese Academy of Sciences Grant XDA12020340, ZSTH-017.

\section{Conflicts of Interest}

None declared.

\section{References}

1. Zhang Y. Why do we study animal toxins? Zool Res 2015; 36: 183-222.

2. Abdul HM, Yang S, Ren L. Centipede Venoms and Their Components: Resources for Potential Therapeutic Applications. Toxins 2015; 7: 4832-4851.
3. Eisner T, Meinwald J, Attyqalle AB, et al. Rendering the inedible edible: circumvention of a millipede's chemical defense by a predaceous beetle larva. Proc Natl Acad Sci USA 1998; 95: 1108-1113.

4. Dadashipour M, Ishida Y, Yamamoto K, et al. Discovery and molecular and biocatalytic properties of hydroxynitrile lyase from an invasive millipede, Chamberlinius hualienensis. Proc Natl Acad Sci USA 2015; 112: 10605-10610.

5. Kuwahara Y, Ichiki Y, Morita M, et al. Chemical polymorphism in defense secretions during ontogenetic development of the millipede Niponia nodulosa. J Chem Ecol 2015; 41: 15-21.

6. Gubb D, Sanz-Parra A, Barcena L, et al. Protease inhibitors and proteolytic signalling cascades in insects. Biochimie 2010; 92: 1749-1759.

7. Peng K, Yi K, Lei Z, et al. Two novel antimicrobial peptides from centipede venoms. Toxicon 2010; 55: 274-279.

8. Yang S, Liu Z, Xiao Y, et al. Chemical punch packed in venoms makes centipedes excellent predators. Mol Cell Proteomics 2012; 11: 640-650.

9. Ma H, Xiao-Peng T, Yang SL, et al. Protease inhibitor in scorpion (Mesobuthus eupeus) venom prolongs the biological activities of the crude venom. Chin J Nat Med 2016; 14: 607-614.

10. Gulliani GL, Hyun BH, Litten MB. Blood recalcification time. A simple and reliable test to monitor heparin therapy. Am J Clin Pathol 1976; 65: 390-396.

11. He W, Wu JJ, Ning J, et al. Inhibition of human cytochrome P450 enzymes by licochalcone A, a naturally occurring constituent of licorice. Toxicol In Vitro 2015; 29: 1569-1576.

12. Jung WK, Kim SK. Isolation and characterisation of an anticoagulant oligopeptide from blue mussel, Mytilus edulis. Food Chem 2009; 117: 687-692.

13. Jing T, Fang Y, Han Y, et al. YY-39, a tick anti-thrombosis peptide containing RGD domain. Peptides 2015; 68: 99-104.

14. Sasaki SD, Cotrin SS, Carmona AK, et al. An unexpected inhibitory activity of Kunitz-type serine proteinase inhibitor derived from Boophilus microplus trypsin inhibitor on cathepsin L. Biochem Biophys Res Commun 2006; 341: 266-272.

15. Liao M, Zhou J, Gong H, et al. Hemalin, a thrombin inhibitor isolated from a midgut cDNA library from the hard tick Haemaphysalis longicornis. J Insect Physiol 2009; 55: 164-173.

16. Macedo-Ribeiro S, Almeida C, Calisto BM, et al. Isolation, cloning and structural characterisation of boophilin, a multifunctional Kunitz-type proteinase inhibitor from the cattle tick. PLoS One 2007; 3: e1624.

17. Ren L, Takeuchi H, Jonczy J, et al. A thrombin inhibitor from the ixodid tick, Amblyomma hebraeum. Gene 2004; 342: 243-249.

18. von Reumont BM, Blanke A, Richter S, et al. The first venomous crustacean revealed by transcriptomics and functional morphology: remipede venom glands express a unique toxin cocktail dominated by enzymes and a neurotoxin. Mol Biol Evol 2014; 31: 48-58.

19. Ma D, Wang Y, Yang H, et al. Anti-thrombosis repertoire of blood-feeding horsefly salivary glands. Mol Cell Proteomics 2009; 8: 2071-2079.

20. Xu X, Yang H, Ma D, et al. Toward an understanding of the molecular mechanism for successful blood feeding by coupling proteomics analysis with pharmacological testing of horsefly salivary glands. Mol Cell Proteomics 2008; 7: 582-590.

21. Rong M, Liu J, Zhang M, et al. A sodium channel inhibitor ISTX-I with a novel structure provides a new hint at the evolutionary link between two toxin folds. Sci Rep 2016; 6: 29691.

22. Ribeiro JM, Makoul GT, Levine J, et al. Antihemostatic, antiinflammatory, and immunosuppressive properties of the saliva of a tick, Ixodes dammini. J Exp Med 1985; 161: 332-344.

23. Zhou Z, Yang $\mathrm{H}, \mathrm{Xu} \mathrm{X}$, et al. The first report of kininogen from invertebrates. Biochem Biophys Res Commun 2006; 347: 1099-1102.

24. Yang $\mathrm{H}, \mathrm{Xu} \mathrm{X}, \mathrm{Ma} \mathrm{D}$, et al. A phospholipase Al platelet activator from the wasp venom of Vespa magnifica (Smith). Toxicon 2008; 51: 289-296.

25. Smith JJ, Hill JM, Little MJ, et al. Unique scorpion toxin with a putative ancestral fold provides insight into evolution of the inhibitor cystine knot motif. Proc Natl Acad Sci USA 2011; 108: 10478-10483.

26. Wang XH, Connor M, Smith R, et al. Discovery and characterization of a family of insecticidal neurotoxins with a rare vicinal disulfide bridge. Nat Struct Biol 2000; 7: 505-513.

27. Yang S, Yang F, Wei N, et al. A pain-inducing centipede toxin targets the heat activation machinery of nociceptor TRPV1. Nat Commun 2015; 6: 284a-284a. 
28. Yang S, Xiao Y, Kang D, et al. Discovery of a selective NaV1.7 inhibitor from centipede venom with analgesic efficacy exceeding morphine in rodent pain models. Proc Natl Acad Sci USA 2013; 110: 17534-17539.

29. Cao Z, Yu Y, Wu Y, et al. The genome of Mesobuthus martensii reveals a unique adaptation model of arthropods. Nat Commun. 2011; 4: 2602-2602.

30. Smith JJ, Hill JM, Little MJ, et al. Unique scorpion toxin with a putative ancestral fold provides insight into evolution of the inhibitor cystine knot motif. Proc Natl Acad Sci USA 2011; 108: 10478-10483.

31. Wang XH, Connor M, Smith R, et al. Discovery and characterization of a family of insecticidal neurotoxins with a rare vicinal disulfide bridge. Nat Struct Biol 2000; 7: 505-513.

32. Liu Z, Cai T, Zhu Q, et al. Structure and function of hainantoxin-III, a selective antagonist of neuronal tetrodotoxin-sensitive voltage-gated sodium channels isolated from the Chinese bird spider Ornithoctonus hainana. J Biol Chem 2013; 288: 20392-20403.
33. Mourão $\mathrm{CB}$, Schwartz EF. Protease inhibitors from marine venomous animals and their counterparts in terrestrial venomous animals. Mar Drugs 2013; 11: 2069-2112.

34. Siemens J, Zhou S, Piskorowski R, et al. Spider toxins activate the capsaicin receptor to produce inflammatory pain. Nature 2006; 444: 208-212.

35. Bohlen CJ, Priel A, Zhou S, et al. A bivalent tarantula toxin activates the capsaicin receptor, TRPV1, by targeting the outer pore domain. Cell. 2010; 141: 834-845.

36. Branco VG, Iqbal A, Alvarez-Flores MP, et al. Amblyomin-X having a Kunitztype homologous domain, is a noncompetitive inhibitor of FXa and induces anticoagulation in vitro and in vivo. Biochim Biophys Acta 2016; 1864: 1428-1435.

37. Huang ZF, Wun TC, Broze GJ Jr.Kinetics of factor Xa inhibition by tissue factor pathway inhibitor. J Biol Chem 1993; 268: 26950-26955.

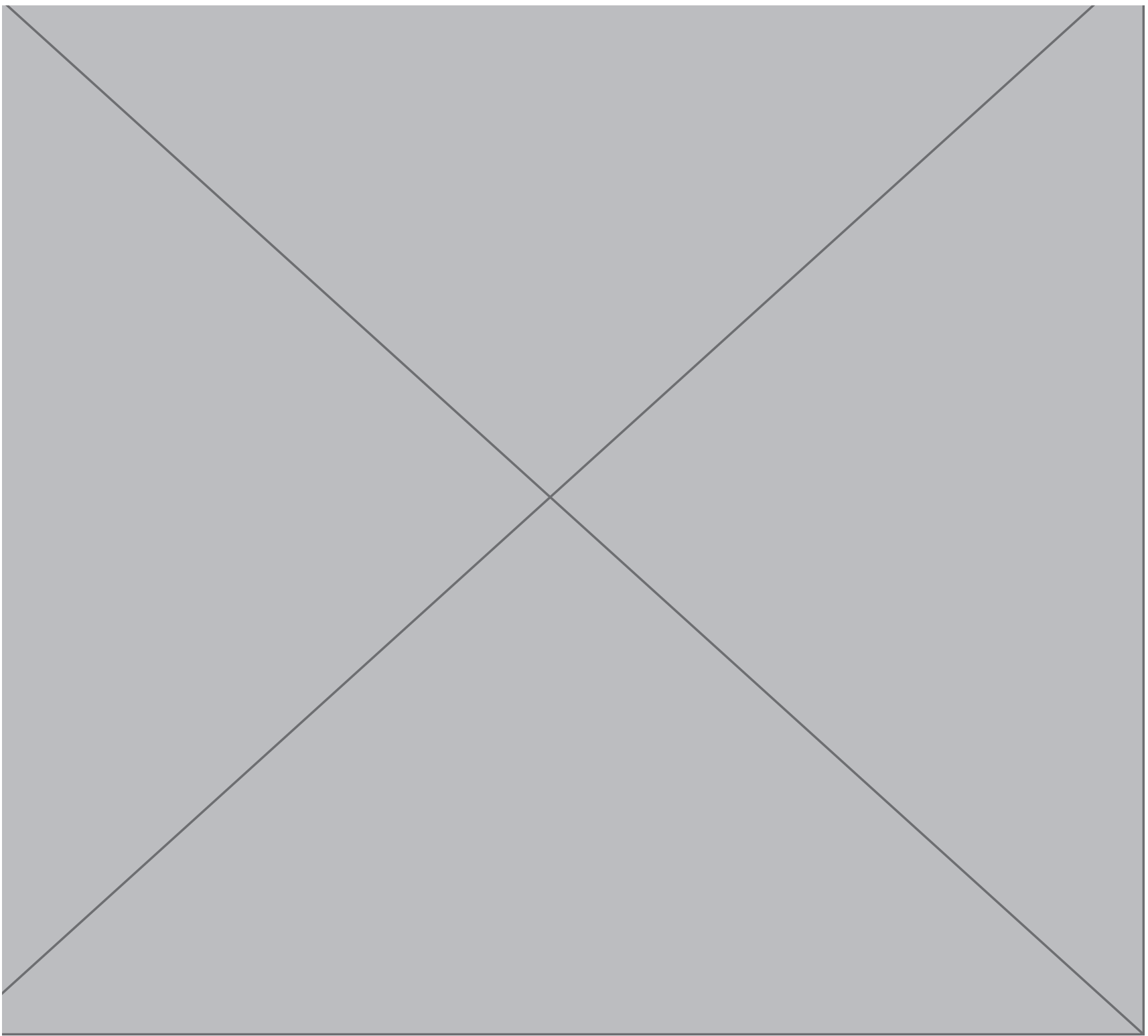

